\title{
The Antibiotic Use in Osteomyelitis Infection: A Systematic Review
}

\author{
Panji Sananta $^{1 *}$ (D), Thomas Erwin Christian Junus Huwae ${ }^{1}$, Daniel Ronadi² ${ }^{\mathbb{D}}$, Lasa Dhakka Siahaan ${ }^{1}$ (D) \\ ${ }^{1}$ Department of Orthopaedic and Traumatology, Faculty of Medicine, Universitas Brawijaya, RSUD Dr. Saiful Anwar, Malang, \\ Indonesia; ${ }^{2}$ Department of Surgery, Faculty of Medicine, Universitas Brawijaya, RSUD Dr. Saiful Anwar, Malang, Indonesia
}

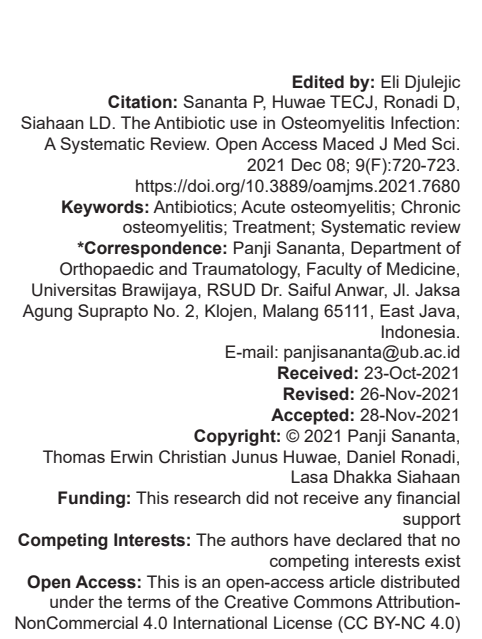

\section{Abstract}

BACKGROUND: Osteomyelitis is a serious infection of the bone. One of the therapies for osteomyelitis is antibiotic treatment. Antibiotic treatment has evolved substantially, but bone infections are still a challenge. Antimicrobial therapy is also difficult, caused by antibiotic-resistant organisms. Therefore, a systematic review is needed to assess antibiotic use in osteomyelitis infection.

METHODS: Articles were searched using PubMed with keywords "antibiotics," "osteomyelitis," and its combination. The authors used 5 years publication date and English language to select the appropriate journal.

RESULTS: The author identified 13 relevant articles with antibiotics use in osteomyelitis. All of the cases were about chronic osteomyelitis and osteomyelitis in diabetic foot ulcers. Osteomyelitis in other sites of long bones needs longer duration treatment than long bone osteomyelitis. In acute osteomyelitis in children, antibiotic treatment can switch from IV to oral antibiotics. Furthermore, chronic osteomyelitis needs longer treatment to resolve than acute osteomyelitis.

CONCLUSION: Antibiotics still mainstay treatment with surgery for osteomyelitis treatment. With acute, children, and long bone only need shorter treatment than chronic, adult, and non-long bone osteomyelitis.

\section{Introduction}

Osteomyelitis is a serious infection of the bone that can be either acute or chronic [1]. The annual incidence of osteomyelitis was 21.8 cases $/ 100.000$ person-years. Rates increased, from 11.4 cases/100.000 person-years from 1969 to 1979 to $24.4 / 100.000$ personyears in the period from 2000 to 2009 [2]. There is still limited data about osteomyelitis incidence in Indonesia. However, there is data from the orthopedic department in Hasan Sadikin Hospital in Bandung, the incidence of chronic osteomyelitis in Indonesia is 0.5-2.4/100.000 populations. And from a study, they found 151 cases of chronic osteomyelitis in Hasan Sadikin Hospital from 2011 to 2016 [3].

Antibiotics are one of the therapies for osteomyelitis. Antibiotics treatment of osteomyelitis has evolved substantially over the past 80 years. Numerous antimicrobial agents with distinct spectrums of action, pharmacokinetics, and pharmacodynamics have been used in its treatment. Surgical techniques, including muscle grafts, llizarov technique, and antibiotic bone cement, have been applied for osteomyelitis. However, bone infections are still a challenge [4]. New studies challenge the dogma, and for example, the antimicrobial must be given parenterally [5]. Antimicrobial therapy is now also difficult by the increasing prevalence of antibiotic-resistant organisms, especially methicillinresistant Staphylococcus aureus [6]. Therefore, a systematic review is needed to assess the antibiotics used in osteomyelitis infection.

\section{Methods}

The following strategy was used terms on the PubMed search engine were "antibiotics," "osteomyelitis," and its combination. Preferred Reporting Items for Systematic Reviews and Meta-Analyses guidelines were used to perform the comprehensive data collection. A bibliometric evaluation was done on all the search results. After searching those keywords, the authors used 5 years of the publication date and English language to select the appropriate journal and documents. Journals and documents were reviewed from title and abstract and followed inclusion and exclusion criteria. The inclusion criteria were an original article, with type are a clinical trial, meta-analysis, or randomized controlled trial which discuss antibiotics 
use in osteomyelitis. The exclusion criteria were case reports, review articles, and no full-text paper. Journal search strategy showed in Figure 1.

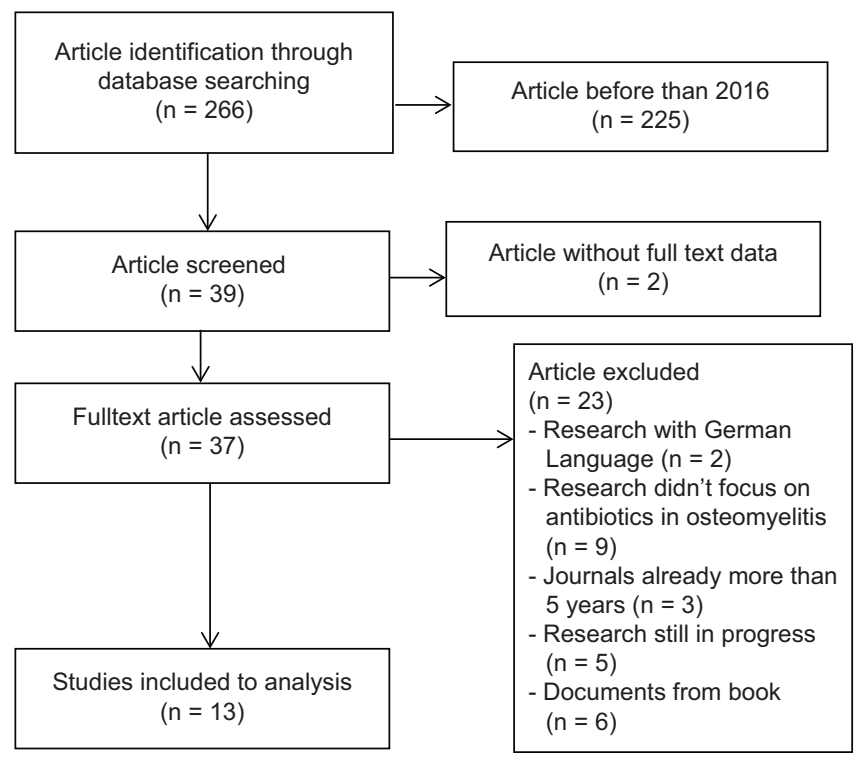

Figure 1: Flow diagram of the search strategy

\section{Results}

The initial PubMed search yielded 266 titles with 39 full-text articles and documents assessed according to the inclusion and exclusion criteria. There were 253 articles and documents eliminated according to the exclusion criteria. The final total number of articles analyzed was 13 articles and documents.

Based on Table 1, the most of the cases from this journal are chronic osteomyelitis and diabetic foot ulcers. Four studies used the retrospective cohort method, six studies used the prospective method, and four studies were review articles. The total number of patients was 5419 samples, with the largest number of samples in a study by Huang et al., 2019, which had 3598 patients with lower extremity osteomyelitis.

Table 1: Studies included to the analysis

\begin{tabular}{llll}
\hline Author & $\Sigma$ Sample & Design & Case \\
\hline Menetrey et al., 2018 [7] & 17 & Prospective & Osteomyelitis, hip surgery \\
Alcobendas et al., 2018 [8] & 253 & Prospective & Osteomyelitis and septic arthritis \\
Chen et al., 2017 [9] & 1526 & Prospective & Osteomyelitis, diabetic foot ulcer \\
Mangwani et al., 2016 [10] & 100 & Prospective & Toe osteomyelitis \\
Huang et al., 2019 [11] & 3598 & Review & Osteomyelitis \\
Lavery et al., 2020 [12] & 155 & Prospective & Osteomyelitis, diabetic foot ulcer \\
Lemaignen et al.., 2017 [13] & 394 & Retrospective & Vertebral osteomyelitis \\
Luo et al., 2016 [14] & 51 & Retrospective & Chronic osteomyelitis \\
Mortazavi et al., 2018 [15] & 183 & Review & Chronic osteomyelitis \\
Van Vugt et al., 2018 [16] & 413 & Review & Chronic osteomyelitis \\
Wunsch et al., 2019 [17] & 101 & Retrospective & Tibial Osteomyelitis \\
Sun et al., 2018 [18] & 72 & Retrospective & Chronic osteomyelitis \\
Graaf et al., 2017 [19] & 313 & Prospective & Acute osteomyelitis in children \\
\hline
\end{tabular}

Based on the Table 2, all of the studies agree with antibiotics as one of the treatments for osteomyelitis besides thesurgery. Fourstudies use chronicosteomyelitis cases for their study. From the site of osteomyelitis, the most studies use lower extremity osteomyelitis cases.
Table 2: Summary antibiotics use in osteomyelitis

\begin{tabular}{|c|c|c|}
\hline Author & Case & Antibiotics use \\
\hline Menetrey et al., 2018 [7] & $\begin{array}{l}\text { Osteomyelitis, hip } \\
\text { surgery }\end{array}$ & $\begin{array}{l}\text { Duration is } 4 \text { to } 6 \text {, with chronic is } 8 \text { to } \\
12 \text { weeks }\end{array}$ \\
\hline Alcobendas et al., 2018 [8] & $\begin{array}{l}\text { Osteomyelitis and } \\
\text { septic arthritis }\end{array}$ & $\begin{array}{l}\text { Oral antibiotics save and effective in } \\
\text { children case }\end{array}$ \\
\hline Chen et al., 2017 [9] & $\begin{array}{l}\text { Osteomyelitis, } \\
\text { diabetic foot ulcer }\end{array}$ & $\begin{array}{l}\text { Osteomyelitis in diabetic foot related to } \\
\text { drug resistant infection }\end{array}$ \\
\hline Mangwani et al., 2016 [10] & Toe osteomyelitis & $\begin{array}{l}\text { Prophylactic antibiotic does not reduce } \\
\text { incidence osteomyelitis in the toe }\end{array}$ \\
\hline Huang et al., 2019 [11] & Osteomyelitis & $\begin{array}{l}\text { Short course antibiotics ( }<4 \text { weeks) as } \\
\text { effective as long course }\end{array}$ \\
\hline Lavery et al., 2020 [12] & $\begin{array}{l}\text { Osteomyelitis, } \\
\text { diabetic foot ulcer }\end{array}$ & $\begin{array}{l}\text { Duration of antibiotics for osteomyelitis } \\
\text { did not change even use NPWT as } \\
\text { treatment }\end{array}$ \\
\hline $\begin{array}{l}\text { Lemaignen et al., } \\
2017 \text { [13] }\end{array}$ & $\begin{array}{l}\text { Vertebral } \\
\text { osteomyelitis }\end{array}$ & $\begin{array}{l}\text { Majority of the case in acute vertebral } \\
\text { osteomyelitis received antibiotics in } \\
90 \text { days }\end{array}$ \\
\hline Luo et al., 2016 [14] & $\begin{array}{l}\text { Chronic } \\
\text { osteomyelitis }\end{array}$ & $\begin{array}{l}\text { Combination therapy (with loaded } \\
\text { calcium sulfate) have better results than } \\
\text { monotherapy }\end{array}$ \\
\hline Mortazavi et al., 2018 [15] & $\begin{array}{l}\text { Cranial } \\
\text { osteomyelitis }\end{array}$ & Broad-spectrum antibiotics 8-20 weeks \\
\hline Van Vugt et al., 2018 [16] & $\begin{array}{l}\text { Chronic } \\
\text { osteomyelitis }\end{array}$ & $\begin{array}{l}\text { The use of antibiotic-loaded sponges in } \\
\text { the treatment of osteomyelitis is limited }\end{array}$ \\
\hline Wunsch et al., 2019 [17] & $\begin{array}{l}\text { Tibial } \\
\text { Osteomyelitis }\end{array}$ & $\begin{array}{l}\text { Dalvabancin as alternative antibiotics for } \\
\text { osteomyelitis }\end{array}$ \\
\hline Sun et al., 2018 [18] & $\begin{array}{l}\text { Chronic } \\
\text { osteomyelitis }\end{array}$ & $\begin{array}{l}\text { Implanted antibiotics can improve results } \\
\text { for chronic osteomyelitis }\end{array}$ \\
\hline Graaf et al., 2017 [19] & $\begin{array}{l}\text { Acute } \\
\text { osteomyelitis in } \\
\text { children }\end{array}$ & $\begin{array}{l}\text { IV switch to oral antibiotic }<7 \text { weeks } \\
\text { have a better outcome than }>7 \text { days }\end{array}$ \\
\hline
\end{tabular}

One article discusses cranial osteomyelitis and one article discusses vertebral osteomyelitis. Furthermore, from age perception, two journals focus on osteomyelitis in children, while the other journal discusses general osteomyelitis in children and adults.

Based on the Table 3, all of the studies said $S$. aureus is the most common etiology of osteomyelitis. Another microorganism who also found in many studies is Streptococcus, even not as many as Staphylococcus. Three studies do not mention the specific organism for the etiology of osteomyelitis.

Cephalosporine and quinolone became the first choice in ten studies, while the other studies used other antibiotics or did not mention the choice.

\section{Discussion}

This systematic review shows that antibiotics are one of the treatments for osteomyelitis besides surgery. In many cases, even in children or adults, in acute or chronic conditions, and many locations, such as extremity, spinal, and cranial, antibiotics, still have a crucial part of therapy for the patient, although every case has a different approach.

An observational study by Lemaignen et al. showed that antibiotics therapy in vertebral osteomyelitis needs a long treatment time. The median duration of antibiotics treatment was 90 days, with only $27.1 \%$ of cases received less than 45 days of antibiotics treatment [13]. In the other study, a comprehensive review from Mortazavi, the result was that an appropriate broadspectrum antibiotics therapy for 8-20 weeks is one of the 
Table 3: Summary of microorganism and choice of antibiotics

\begin{tabular}{|c|c|c|}
\hline Author & Microorganism & Choice of antibiotics \\
\hline Menetrey et al., 2018 [7] & S. aureus & Afabicin \\
\hline Alcobendas et al., 2018 [8] & S. aureus, Kingella kingae & Cephalosporin, amoxicillin-clavulanate, clindamycin \\
\hline Chen et al., 2017 [9] & Methicillin-Resistant $S$. aureus (MRSA) & No specific antibiotics \\
\hline Mangwani et al., 2016 [10] & No specific microorganism & Flucloxacillin \\
\hline Huang et al., 2019 [11] & No specific microorganism & No specific antibiotics \\
\hline Lavery et al., 2020 [12] & No specific microorganism & No specific antibiotics \\
\hline Lemaignen et al., 2017 [13] & S. aureus, Enterobacteria, Streptococci & $\begin{array}{l}\text { Anti-staphylococcal beta-lactam/Fluoroquinolone + rifampicin, } 3^{\text {rd }} \text { gen } \\
\text { cephalosporin and/or fluoroquinolone, amoxicillin }\end{array}$ \\
\hline Luo et al., 2016 [14] & S. aureus, MRSA, $P$. aeruginosa & Levofloxacin, Cefazolin, Ceftazidime, Vancomycin + calcium sulfate (local) \\
\hline Mortazavi et al., 2018 [15] & S. aureus, Streptococci, anaerob microorganism & Carbapenem + ciprofloxacin \\
\hline Van Vugt et al., 2018 [16] & S. aureus, Escherichia coli & Gentamycin-sulfate/gentamycin-crobefate implant \\
\hline Wunsch et al., 2019 [17] & S. aureus, MRSA, Enterococci, Streptococci, Propionibacterium acne & Dalvabancin \\
\hline Sun et al., 2018 [18] & S. aureus, Klebsiella, E. coli, Streptococcus pneumonia & Broad-spectrum antibiotics + Gentamycin (for impregnated bead) \\
\hline Graaf et al., 2017 [19] & S. aureus, K. kingae, Streptococcus & Flucloxacillin and ceftriaxone \\
\hline
\end{tabular}

essential therapies to managing cranial osteomyelitis. Nevertheless, culture-directed antimicrobial therapy for a minimum of three months remains the general protocol because the treatment of cranial osteomyelitis may take several months for complete resolution [15]. In other studies, the diabetic foot becomes one of the main factors for how long the antibiotics must be given. From a journal by Huang et al., the patients with diabetic foot and osteomyelitis need more than 3 months of antibiotics for non-surgically treated patients. This journal also said that patients with vertebral osteomyelitis are treated with 6 weeks of antibiotics, but the chronic osteomyelitis of the long bones need a 4-6 weeks course of parenteral antibiotics, followed by oral therapy [11].

The results of antibiotics treatment in chronic osteomyelitis also have different results between children and adults. Hanley et al., in their journal, said that surgical debridement and culture-directed antibiotics are the mainstays of treatment. Furthermore, if after the appropriate therapy for 4-6 weeks has finished but the osteomyelitis still cannot be resolved, the diagnosis of chronic refractory osteomyelitis (CRO) becomes appropriate [20]. Hence, the conclusion is the standard duration of antibiotics treatment for osteomyelitis is 4-6 weeks. However, another journal researched the duration in children cases by Alcobendas et al. In their study, they compare the treatment adjusted by age. The result was that $S$. aureus was more prevalent in older children, while Kingella kingae was more frequent in younger children. In $75 \%$ of cases still need surgical treatment because of the protocol or diagnostic purpose. K. kingae infection involves a less severe process, allowing quick oral therapy. This research suggested IV antibiotics for 2-4 days, followed by oral antibiotics for 2-3 weeks [8]. Journal from Graaf also said that the suggested duration for the parenteral antibiotic treatment ranges from 3 days to 6 weeks, but this recommendation has a relatively poor level of evidence. However, a recent retrospective cohort study of 1969 children in the USA found that early switch to oral therapy (median 4 days) was as effective as prolonged intravenous treatment [19].

Antibiotics treatment duration in chronic osteomyelitis is longer than antibiotics treatment in acute osteomyelitis. One of the journals said that acute osteomyelitis would respond to the therapy for
4-6 weeks, and if not, the diagnosis of CRO becomes appropriate [18], [20]. In chronic osteomyelitis, multitherapy antibiotics can give better results than monotherapy, and oral antibiotics were not administered in most journals.

From the etiology, almost every journal said $S$. aureus is the most common etiology of osteomyelitis. Only three studies do not mention the microorganism. S. aureus is part of normal flora, but in some situations, $S$. aureus becomes virulent with a well-armed pathogen [21]. Extensive virulence factors and increased resistance of virulence pathogen make a "new face" of $S$. aureus like MRSA. This condition has a bad impact on decreasing $S$. aureus infection. Another etiology is Streptococci, a flora normal and common pathogen beyond the neonatal period through the age of four. However, now become rare because of the vaccination and replaced by $K$. kingae [22].

Antibiotics choice has also become a topic until right now. In osteomyelitis cases, the antibiotics need an excellent penetration into bone and joint tissue to eradicate the microorganism. A literature studied more than 30 antibiotics, and the results almost all antibiotics have good penetration in bone and joint. Of note, studies on joint space penetration were fewer than studies on bone tissue penetration. However, flucloxacillin had poor profiles in terms of joint space penetration [23]. All studies still believe antibiotics are a mainstay treatment for osteomyelitis and culture directed antibiotics for specific etiology. Most of the studies choose beta-lactam and fluoroquinolone for antibiotics treatment. Beta-lactam agents are the drugs of choice for treating Osteomyelitis in Neonatal and children due to K. kingae, Group $A$ Streptococcus, or Streptococcus pneumonia [24].

\section{Conclusion}

Antibiotics still mainstay treatment with surgery for osteomyelitis treatment. In acute, children, and long bone only cases, they need shorter treatment than chronic, adult, and non-long bone osteomyelitis. Most of the etiology of osteomyelitis is $S$. aureus 
and cephalosporin as beta-lactam antibiotics, and fluoroquinolone is still the drug of choice in culture directed antibiotics treatment for osteomyelitis.

\section{References}

1. Momodu II, Savaliya V. Osteomyelitis. In: Stat Pearls. Treasure Island, FL: Stat Pearls Publishing; 2021.

2. Kremers HM, Nwojo ME, Ransom JE, Wood-Wentz CM, Melton LJ $3^{\text {rd }}$, Huddleston PM $3^{\text {rd }}$. Trends in the epidemiology of osteomyelitis: A population-based study, 1969 to 2009. J Bone Joint Surg Am. 2015;97(10):837-45. https://doi.org/10.2106/ JBJS.N.01350

\section{PMid:25995495}

3. Indira SA, Lokarjana L, Pohan DK. Gambaran Pasien Osteomyelitis Kronis di Bagian Bedah Ortopedi RSUP dr. Hasan Sadikin Bandung, Repository Unjani; 2017. p. 610.

4. Jorge LS, Chueire AG, Rossit AR. Osteomyelitis: A current challenge. Braz J Infect Dis. 2010;14(3):310-5.

PMid:20835519

5. Cortés-Penfield NW, Kulkarni PA. The history of antibiotic treatment of osteomyelitis. Open Forum Infect Dis. 2019;6(5):ofz181. https://doi.org/10.1093/ofid/ofz181 PMid:31123692

6. Rao N, Ziran BH, Lipsky BA. Treating osteomyelitis: Antibiotics and surgery. Plast Reconstr Surg. 2011;127 Suppl 1:177S-87S. https://doi.org/10.1097/PRS.0b013e3182001fOf PMid:21200289

7. Menetrey A, Janin A, Pullman J, Overcash JS, Haouala A Leylavergne $\mathrm{F}$, et al. Bone and joint tissue penetration of the Staphylococcus-selective antibiotic afabicin in patients undergoing elective hip replacement surgery. Antimicrob Agents Chemother. 2019;63(3):e01669-18. https://doi.org/10.1128/ AAC.01669-18

PMid:30559136

8. Alcobendas R, Remesal A, Murias S, Nuñez E, Calvo C. Outpatients with acute osteoarticular infections had favourable outcomes when they received just oral antibiotics without intravenous antibiotics. Acta Paediatr. 2018;107(10):1792-7. https://doi.org/10.1111/apa.14373

PMid:29705992

9. Chen $\mathrm{Y}$, Ding $\mathrm{H}, \mathrm{Wu} \mathrm{H}$, Chen $\mathrm{HL}$. The relationship between osteomyelitis complication and drug-resistant infection risk in diabetic foot ulcer: A meta-analysis. Int J Low Extrem Wounds. 2017;16(3):183-90. https://doi.org/10.1177/1534734617728642 PMid:28862037

10. Mangwani J, Gulati A, Benson R, Cichero M, Williamson DM Role of prophylactic antibiotics in lesser toe fusion surgery: A prospective randomised controlled trial. Foot Ankle Surg. 2017;23(1):50-2. https://doi.org/10.1016/j.fas.2016.02.004 PMid:28159043

11. Huang CY, Hsieh RW, Yen HT, Hsu TC, Chen CY, Chen YC, et al. Short-versus long-course antibiotics in osteomyelitis: A systematic review and meta-analysis. Int $\mathrm{J}$ Antimicrob Agents. 2019;53(3):246-60. https://doi.org/10.1016/j. ijantimicag.2019.01.007 PMid:30639627

12. Lavery LA, Davis KE, La Fontaine J, Farrar JD, Bhavan K, Oz OK et al. Does negative pressure wound therapy with irrigation improve clinical outcomes? A randomized clinical trial in patients with diabetic foot infections. Am J Surg. 2020;220(4):1076-82. https://doi.org/10.1016/j.amjsurg.2020.02.044

PMid:32139102

13. Lemaignen A, Ghout I, Dinh A, Gras G, Fantin B, Zarrouk V, et al. Characteristics of and risk factors for severe neurological deficit in patients with pyogenic vertebral osteomyelitis: A casecontrol study. Medicine (Baltimore). 2017;96(21):e6387. https:// doi.org/10.1097/MD.0000000000006387 PMid:28538361

14. Luo $S$, Jiang $T$, Yang $Y$, Yang $X$, Zhao J. Combination therapy with vancomycin-loaded calcium sulfate and vancomycinloaded PMMA in the treatment of chronic osteomyelitis. BMC Musculoskelet Disord. 2016;17(1):502. https://doi.org/10.1186/ s12891-016-1352-9

PMid:28007027

15. Mortazavi MM, Khan MA, Quadri SA, Suriya SS Fahimdanesh KM, Fard SA, et al. Cranial osteomyelitis: A comprehensive review of modern therapies. World Neurosurg. 2018;111:142-53. https://doi.org/10.1016/j.wneu.2017.12.066 PMid:29253689

16. van Vugt TA, Walraven JM, Geurts JA, Arts JJ. Antibioticloaded collagen sponges in clinical treatment of chronic osteomyelitis: A systematic review. J Bone Joint Surg Am. 2018;100(24):2153-61. https://doi.org/10.2106/JBJS.17.01140 PMid:30562296

17. Wunsch S, Krause R, Valentin T, Prattes J, Janata O, Lenger A et al. Multicenter clinical experience of real life Dalbavancin use in gram-positive infections. Int J Infect Dis. 2019;81:210-4. https://doi.org/10.1016/j.ijid.2019.02.013

PMid:30794940

18. Sun $P Q, M a Y$, Zhang $Y C$, Cheng MG. Application of antibiotic impregnated beads on the patients with tibial chronic osteomyelitis. Pak J Pharm Sci. 2018;31(6):2783-6.

PMid:30630784

19. Hanley ME, Hendriksen S, Cooper JS. Hyperbaric treatment of chronic refractory osteomyelitis. In: Stat Pearls. Treasure Island, FL: Stat Pearls Publishing; 2021.

PMid:28613536

20. Graaf H, Sukhtankar P, Arch B, Ahmad N, Lees A, Bennett A, et al. Duration of intravenous antibiotic therapy for children with acute osteomyelitis or septic arthritis: A feasibility study. Health Technol Assess. 2017;21(48):1-164. https://doi.org/10.3310/ hta21480

PMid:28862129

21. Archer GL. Staphylococcus aureus: A well-armed pathogen. Clin Infect Dis. 1998;26(5):1179-81. https://doi.org/10.1086/520289 PMid:9597249

22. DeRonde KJ, Girotto JE, Nicolau DP. Management of pediatric acute hematogenous osteomyelitis, Part I: Antimicrobial stewardship approach and review of therapies for methicillinsusceptible Staphylococcus aureus, Streptococcus pyogenes, and Kingella kingae. Pharmacotherapy. 2018;38(9):947-66. https://doi.org/10.1002/phar.2160

PMid:29920709

23. Thabit AK, Fatani DF, Bamakhrama MS, Barnawi OA, Basudan LO, Alhejaili SF. Antibiotic penetration into bone and joints: An updated review. Int J Infect Dis. 2019;81:128-136. https://doi.org/10.1016/j.ijid.2019.02.005 PMid:30772469

24. Thakolkaran N, Shetty AK. Acute hematogenous osteomyelitis in children. Ochsner J. 2019;19(2):116-22. https://doi. org/10.31486/toj.18.0138

PMid:31258423 